\title{
O cotidiano do cuidado no domicílio: a realidade de crianças e adolescentes com mielomeningocele
}

\author{
Home care daily: the reality of children and adolescents with myelomeningocele \\ Giselle Lima de Freitas ${ }^{1 *}$, Fabiana Faleiros², Naira Beatriz Favoretto ${ }^{3}$, Filipe Gustavo Lopes ${ }^{4}$, Bruna \\ Figueiredo Manzo ${ }^{5}$, Elysângela Dittz Duarte ${ }^{6}$
}

\begin{abstract}
${ }^{1}$ Doutorado em enfermagem pela Universidade Federal de Minas Gerais; ${ }^{2}$ Pós-doutorado em reabilitação pela Universidade de Michigan - Estados Unidos; ${ }^{3}$ Doutorado no programa de Ciências da Reabilitação da Universidade de Dortmund-Alemanha; ${ }^{4}$ Mestrado em Reabilitação e Desempenho Funcional pela Universidade Federal dos Vales do Jequitinhonha e Mucuri; ${ }^{5}$ Doutorado em enfermagem pela Universidade Federal de Minas Gerais; ${ }^{6}$ Pós-doutorado na School of Nursing/UNC-Chapel Hill
\end{abstract}

\begin{abstract}
Resumo
Introdução: crianças e adolescentes com mielomeningocele atingem a idade adulta devido ao avanço médico, tecnológico e no tratamento, no entanto, ainda enfrentam repercussões que comprometem seu cotidiano e qualidade de vida. Objetivo: analisar o cotidiano de crianças e adolescentes com mielomeningocele. Metodologia: estudo exploratório, com abordagem qualitativa, utilizando-se o referencial teórico de Agnes Heller, na perspectiva do cotidiano. Para a coleta de dados foram entrevistadas 16 mães e 16 crianças e adolescentes com mielomeningocele entre maio e agosto de 2015, residentes em Belo Horizonte/MG e grande região. Resultados: a falta de recursos financeiros, associada às demandas medicamentosas e de insumos para os cuidados, limitou as possibilidades de socialização e participação de crianças e adolescentes. A infraestrutura inadequada de escolas representou uma barreira para a socialização de alguns dos participantes. O cotidiano foi marcado por restrição social, com limitação das atividades de lazer e realização de cuidados domiciliares não habituais. Conclusão: sugere-se a parceria entre diferentes setores da sociedade no intuito de permitir maior participação social a essa população e a construção de políticas públicas direcionadas.

Palavras-chave: Meningomielocele. Criança. Adolescente.
\end{abstract}

\begin{abstract}
Introduction: children and adolescents with myelomeningocele reach adulthood due to medical, technological and treatment advances, however, they still face repercussions that compromise their daily lives and quality of life.Objective: to analyze the daily life of children and adolescents with myelomeningocele. Methods: an exploratory study with a qualitative approach, using Agnes Heller's theoretical framework, from the perspective of daily life. For data collection, 16 mothers and 16 children and adolescents with myelomeningocele were interviewed between May and August 2015, living in Belo Horizonte / MG and large region. Results: the lack of financial resources, associated with drug demands and care inputs, limited the possibilities of socialization and participation of children and adolescents. The inadequate infrastructure of schools represented a barrier to the socialization of some of the participants. The daily life was marked by social restriction, with limitation of leisure activities and performing unusual home care. Conclusion: it is suggested the partnership between different sectors of society in order to allow greater social participation to this population and the construction of targeted public policies.
\end{abstract}

Key words: Meningomyelocele. Child.Adolescent.

\section{INTRODUÇÃO}

A mielomeningocele (MMC) é a mais frequente malformação ocasionada pelo defeito de fechamento do tubo neural (DFTN) e a mais grave compatível com a vida. Caracteriza-se por uma malformação congênita dos ossos que protegem a medula espinhal, acarretando uma lesão medular congênita (MOHD-ZIN et al., 2017). As malformações decorrentes do DFTN correspondem a segunda maior causa de malformações congênitas, pre-

Correspondente/Corresponding: *Giselle Lima de Freitas - End; Av Alfredo Balena, 190, sala 400, Bairro Santa Efigênia, CEP: 30130-100 Belo Hoizonte - Tel: (31) 3409-9868 - E-mail: gisellelf@yahoo.com.br cedida apenas pelos problemas cardíacos (COPP; GREENE, 2013). A MMC também determina a segunda causa de deficiência crônica no aparelho locomotor em crianças (FERREIRA et al., 2018).

As consequências secundárias a essa malformação incluem a ocorrência de Arnold Chiari tipo 2, hidrocefalia, alterações neuropsicológicas associadas à lesão cerebral, diminuição de força e sensibilidade abaixo do nível da lesão, deformidades musculoesqueléticas e, bexiga e intestino neurogênicos (MOHD-ZIN et al., 2017). Dor, úlceras por pressão, depressão, distúrbios do sono e limitada participação social e comunitária são condições secundárias comuns que interferem na qualidade de 
vida de indivíduos com MMC, em todas as faixas etárias (WAGNER et al., 2015).

No Brasil, houve elevação no coeficiente de incidência por espinha bífida entre 1999 e 2004 (DA SILVA; DE OLIVEIRA-MENEGOZZO, 2012). A Agência Nacional de Vigilância Sanitária (ANVISA), em dezembro de 2002, determinou a adição de ácido fólico às farinhas de trigo e de milho no país, com efetiva implantação a partir de junho de 2004 (ORIOLI et al., 2011). Queda significativa dos valores foi encontrada, passando de 20,95 para 15,32 e 13,21/100.000 nascidos vivos em 2004, 2005 e 2006, respectivamente (DA SILVA; DE OLIVEIRA-MENEGOZZO, 2012). No Chile, a prevalência dessa malformação é de 4,2 por 10.000 nascimentos e se observa um aumento da sobrevida em maiores de 17 anos (CORTEZ; SCHULZ; PARDO, 2017). Nos Estados Unidos, a adição de ácido fólico a alguns cereais reduziu o número de nascimentos de crianças com MMC, de 5,04 para 3,49 por 10.000 nascidos vivos (LE; MUKHERJEE, 2015).

Com o tratamento eficaz de complicações comuns, como a hidrocefalia e a bexiga neurogênica, a maioria dos indivíduos com MMC sobrevive até a idade adulta. Há 50 anos, a sobrevivência era de aproximadamente 10\% (FIEGGEN et al., 2014). Os adventos médicos e cirúrgicos como o uso de antibióticos, as derivações para controle da hidrocefalia e o cateterismo vesical para o manejo da bexiga neurogênica proporcionaram o aumento da sobrevida de indivíduos com MMC. Atualmente, 85\% dos nascidos com MMC atingem a fase adulta e o foco é a transição dos cuidados ao longo da adolescência, busca pela independência e autonomia, com abordagem de questões que podem comprometer a qualidade de vida (LE; MUKHERJEE, 2015).

A independência funcional depende do nível da lesão medular e sua avaliação é importante para a determinação de abordagens terapêuticas adequadas e promoção de meios para aquisição de independência para realização de atividades de vida diária e prática e autonomia para gerenciamento da própria vida (FERREIRA et al., 2018). Um estudo de coorte realizado com crianças nascidas com MMC no Reino Unido, embora tenha identificado diminuição na capacidade de caminhar ao longo dos anos, verificou aumento da capacidade de viver de forma independente na comunidade, após os 25 anos (OAKESHOTT et al., 2019). O incentivo à independência e à autonomia favorece o desenvolvimento pessoal e social da criança com MMC, maximiza suas oportunidades futuras de inserção e participação e reduz a sobrecarga do cuidador (CASEIRO; GONÇALVES; MALHEIRO, 2013).

$O$ advento médico e científico permitiu a sobrevivência de recém-nascidos e crianças com MMC, aumentando a expectativa de vida dessa população, que hoje, atinge a fase adulta. Apesar dos estudos ressaltarem a importância da MMC no contexto das malformações pediátricas, há uma escassez de estudos sobre o cotidiano de crianças e adolescentes. Ademais, considera-se a importância de pais e profissionais de saúde estarem preparados para o trabalho de transição de cuidados para os próprios indivíduos com MMC, inserindo em seu cotidiano ações que estimulem a independência para atividades de vida diária e prática, como, por exemplo, o uso de transporte público e a realização de compras, o mais cedo possível.

O cotidiano representa a reprodução do homem particular, que assimila a práxis da vida cotidiana, normas, condutas e comportamentos, para formar seu mundo pelo contato direto com seu ambiente imediato (HELL$E R, 2008)$. Partindo-se do pressuposto que o cotidiano, abordado no referencial de Agnes Heller, representa um suporte para a compreensão da dinâmica de vida de crianças e de adolescentes com MMC, de sua família e daqueles que se articulam para seu cuidado, objetivou-se analisar o cotidiano de crianças e adolescentes com mielomeningocele. Esse estudo poderá contribuir para que os profissionais de saúde repensem sobre as necessidades das crianças, adolescentes e sua família em busca de uma assistência qualificada e integral.

\section{METODOLOGIA}

Pesquisa exploratória, de abordagem qualitativa, que utilizou o referencial teórico de Agnes Heller (2008), na perspectiva do cotidiano, entendido como imagem da reprodução da sociedade a qual o ser humano pertence. A abordagem qualitativa foi escolhida pela potencialidade de possibilitar aproximação à participação dos sujeitos na vida social (MINAYO, 2010).

Os participantes foram 16 mães e 16 crianças e adolescentes com MMC atendidos em um Hospital de Reabilitação, referência no atendimento a esse público, na cidade de Belo Horizonte/Minas Gerais. Foram adotados como critérios de inclusão: crianças e adolescente com idade de 5 a 18 anos (faixa etária de atendimento no cenário do estudo) que participaram do programa de reabilitação entre os anos de 2009 e 2014, residentes em Belo Horizonte e região metropolitana. Os critérios de exclusão foram: crianças e adolescentes com problemas agudos, relatados no momento do convite e que tiveram internações em instituições diferentes do cenário de estudo durante o período da coleta.

Para a seleção dos participantes, verificou-se os atendimentos programados de crianças e adolescentes com MMC para o decorrer do mês de maio de 2015, identificando-se 54 atendimentos registrados. Após consulta aos 54 prontuários e aplicação dos critérios de inclusão e exclusão, identificou-se 26 potenciais participantes. 0 acompanhamento institucional há menos de cinco anos, indivíduos institucionalizados ou vesicostomizados foram as causas das 28 exclusões. Os 26 potenciais participantes foram convidados a participar do estudo sendo, nesse momento, informado da necessidade de participação das crianças e dos adolescentes; houve recusa por parte de 10 deles, referindo problemas de saúde na família, desinteresse e realização de obras no ambiente domiciliar. Portanto, 16 cuidadores, todas mães, e suas crianças e 
adolescentes com MMC, totalizaram os 32 participantes do estudo.

A coleta de dados ocorreu de maio e agosto de 2015, no domicílio dos participantes. Utilizou-se entrevista semi-estruturada e observação. A entrevista foi aplicada aos cuidadores e às crianças e adolescentes sem limitação cognitiva. A observação foi aplicada a ambos. O instrumento de entrevista foi previamente aplicado a quatro mães que não participaram da pesquisa e que estavam internadas na instituição no mês de abril de 2015, como piloto, sendo indicadas e realizadas pequenas alterações com objetivo de facilitar a compreensão das perguntas.

Para a produção dos dados, realizou-se 3 encontros com cada uma das famílias. A entrevista foi realizada apenas no primeiro encontro, com duração média de 45 minutos (tempo total de 10 horas e 36 minutos e 123 páginas). 0 roteiro de entrevista semiestruturado foi elaborado pela pesquisadora utilizando-se de sua experiência profissional no atendimento às crianças, a literatura pertinente e o referencial teórico. Esse instrumento apresentava a caracterização sócio-demográfica dos participantes, a caracterização clínica da criança ou do adolescente e questões abertas que buscavam explorar a realização do cuidado no domicílio, como pessoas que contribuíam para o cuidado, dificuldades e facilidades, adaptações necessárias e custos econômicos.

Utilizou-se a observação com roteiro para facilitar a captação de aspectos pertinentes ao fenômeno da continuidade do cuidado, sendo registrados no diário de campo: informações, fatos, falas, hábitos, conversas informais percebidas como importantes. A realização das visitas domiciliares permitiu a observação de atividades diárias dos participantes e a interação por meio de escuta ativa, diálogo, percepções acerca da realidade cotidiana, que culminavam com a orientação de condutas e a realização de cuidados. Os dados provenientes das observações foram registrados em diário de campo do pesquisador, logo após a realização das visitas. 0 tempo total das observações foi de 52 horas e 37 minutos, com tempo médio de uma hora e oito minutos, por visita.

O material proveniente das entrevistas e das observações foi submetido a Análise de Conteúdo Temática, proposta por Bardin (2009). As entrevistas foram transcritas e codificadas com elementos alfanuméricos, precedidos pela letra " $E$ ", quando relacionava-se a fala materna e " $C$ ", quando relacionada a fala de criança ou adolescente, seguida de identificação numérica referente à ordem em que foram realizadas, sendo codificadas de 1 a 16 (ex.: M.1 - fala materna da primeira entrevista e C. 4 - fala de criança ou adolescente da quarta entrevista). Realizou-se leitura flutuante de todo o material até impregnação pelo conteúdo, buscando a apreensão das ideias e significados. Em seguida, foram agrupadas as unidades de sentido, selecionadas a partir de sua relação com os objetivos do estudo e com as categorias analíticas da cronicidade, da continuidade do cuidado e do cotidiano. Foram construídas duas categorias empíricas: "De casa para a escola" e "Desejo de independência: sonho ou realidade?"

Os aspectos éticos foram respeitados conforme resolução 466/2012 do Conselho Nacional de Saúde (BRASIL, 2012). O projeto foi aprovado pelo Comitê de Ética em Pesquisa da Universidade Federal de Minas Gerais (UFMG), parecer número 1.036.625. Todos os participantes foram esclarecidos do objetivo da pesquisa e assinaram o termo de consentimento livre e esclarecido (TCLE). Os menores de idade assinaram o termo de assentimento livre e esclarecido (TALE).

\section{RESULTADOS}

\section{Caracterização da amostra}

A idade das crianças e adolescentes variou de sete a 17 anos, com média de 12 anos, sendo 13 do sexo feminino e 3 do sexo masculino. Dois adolescentes não frequentavam a escola (C.6 e C.15). A altura da lesão lombar (alta ou baixa) ou lombossacral predominou em dez participantes. A maioria dos participantes, 10 , era não deambulador, e todos possuíam cadeira de rodas; cinco (C.4, C.7, C.8, C.9, C.11) eram deambuladores comunitários, ou seja, com capacidade para percorrer pequenas distâncias na comunidade com auxílio de órteses, e somente um (C.3) era deambulador domiciliar, com auxílio de andador. Identificou-se que apenas dois participantes (C.1 e C.9) não utilizavam medicação de forma regular e três (C.4, C.7, C.9), não apresentavam hidrocefalia. Dos 13 participantes que manifestaram hidrocefalia, um (C.8) possuía derivação espontânea, sem necessidade de instalação de válvula de derivação; sete necessitavam de válvula de derivação, sem trocas; cinco (C.2, C.3, C.10, C.15, C.16) necessitavam de válvula de derivação e trocas subsequentes. Foram duas (C.10 e C.16) as crianças que necessitaram de trocas de válvulas e tiveram comprometimento cognitivo grave devido às complicações. Apenas três adolescentes (C.1, C.4, C.7) eram totalmente independentes para o autocuidado e atividades de vida diária, bem como para a realização de algumas tarefas domésticas.

As mães participantes tinham idade média de 37 anos, 12 eram casadas ou mantinham relação estável e quatro mulheres não possuíam relação estável. Apenas duas mães (M.2 e M.3) possuíam trabalho formal fora do domicílio. A renda familiar média foi de 2,5 salários mínimos vigentes à época e 12 famílias recebiam o Benefício da Prestação Continuada (BPC) garantido pelo Instituto Nacional do Seguro Social (INSS). Quanto à escolaridade, três mulheres declararam possuir o ensino médio incompleto (M.1, M.5, M.13); seis, o ensino médio completo; seis mães referiram possuir o ensino fundamental incompleto e uma declarou ser iletrada (M.8). Duas mães (M.2 e M.11) haviam voltado a estudar recentemente e estavam cursando o ensino superior. 


\section{Categoria Empírica 1: de casa para a escola}

A construção desta categoria evidenciou um cotidiano marcado por idas à escola e o enfrentamento de desafios relacionados à infra-estrutura física e de interação social nesse ambiente. Aborda aspectos relacionados ao cotidiano de crianças e adolescentes com MMC na escola, destacando as principais dificuldades e desafios enfrentados por essa população no atendimento de suas necessidades. São evidenciadas as repercussões no desempenho do autocuidado quando estão no ambiente escolar, na sua inclusão e na interação com os colegas.

Todos os participantes do estudo estavam em idade escolar, contudo, dois adolescentes não frequentavam a escola (C.6 e C.15). Ambos enfrentavam dificuldades com aquisição de transporte escolar. As mães desses adolescentes relataram a inadequação da escola para receber cadeirante, declarando a não existência de rampas de acesso.

Não tem rampa. É cheio de buraco, não dá para ela ir sozinha. Então eu prefiro deixar em casa (M.15).

A alteração do padrão de marcha é uma das sequelas da MMC. Os dez participantes classificados como não deambuladores possuíam cadeira de rodas. $\mathrm{O}$ uso de cadeira de rodas no ambiente escolar exige modificação do ambiente físico, tais como a construção de rampas de acesso e a ampliação de portas que permitam a livre passagem das cadeiras. Ademais, especificamente no caso de crianças e adolescentes com MMC que realizam cateterismo vesical, a escola deve se preparar com a adequação de banheiro que possibilite a realização do procedimento, o que não se detectou no relato das mães e dos próprios adolescentes.

Não é que a escola é adaptada, eles disponibilizam banheiro dos professores (M.4).

A adaptação inadequada da escola pode interferir no desejo em frequentar esse ambiente, comprometendo seu rendimento e desempenho escolar:

Ela faltava. Pegou recuperação, quase que foi reprovada, porque não queria ir para a escola (M.13).

É muito difícil, queria ser olhada como todo mundo (C.15)

Não obstante as limitações causadas por barreiras arquitetônicas ou inadequada infra-estrutura física nas escolas, ficou demonstrado que existe também a dificuldade de acesso a outros ambientes. As mães do estudo afirmaram enfrentar problemas na utilização de transporte público, bem como no deslocamento do local de residência ao ponto de ônibus e outros lugares.
Na verdade, a maior dificuldade que eu tenho com ele é a questão de transporte. É a maior. É a maior de todas (M.5).

Acrescentando-se questões de ordem econômica, como o baixo nível socioeconômico dessas famílias, foi possível encontrar que a maior parte das crianças e dos adolescentes têm o cotidiano marcado pelas idas à escola, sendo o lazer restrito a idas a igrejas e visitas a parentes.

Nosso dia a dia é em casa. A gente não faz nada de lazer... nada (M.6).

Lazer? Passear na casa do primo. Ver o avô. De vez em quando vai ao shopping. Tem shopping aqui perto... É mais é ela brincar lá embaixo mesmo (M.11).

\section{Categoria empírica 2: desejo de independência, sonho ou realidade?}

Esta categoria destaca o desejo de aquisição de independência por crianças e adolescentes com MMC e suas mães e a contradição evidenciada em seus discursos sobre como conquistá-la. "Desejo de independência: sonho ou realidade?" aborda as dificuldades maternas e de indivíduos com MMC para a construção da independência.

Apenas três participantes (C.1, C.4 e C.7), todas do sexo feminino, com idade de 13,10 e 15 anos, eram totalmente independentes para o autocuidado e participavam de atividades domésticas. Duas participantes (C.10 e C.16), também do sexo feminino, com idade de nove e 12 anos, apresentavam grave comprometimento cognitivo e eram totalmente dependentes de suas mães, necessitando de auxílio inclusive para a alimentação.

Os demais participantes do estudo, com idade entre sete e 17 anos, dependiam parcialmente de suas mães para a realização de cuidados. Desses, três (C.8, C.9, C.11) eram deambuladores comunitários, os demais, não deambuladores. Apesar de serem dependentes de suas mães, o desejo por independência e autonomia foi relatado de forma constante no cotidiano desses participantes. O relato das mães dos participantes com potencial para independência, assim como dos próprios adolescentes, propõe forte desejo de independência.

Ela até toma banho só, eu deixo, mas de vez em quando eu dou um faxinão (risos)... Ela escova os dentes e come sozinha. Ela não faz o CAT sozinha... sozinha ainda não... só me ajuda... passando gel... limpando.... (M.2).

Ele já coloca fralda sozinho, Graças a Deus [com uma forte ideia de gratidão e alívio]. Ele não consegue ainda colocar uma das talas (M.5).

Os adolescentes com potencial para independência manifestaram o desejo de se tornarem independentes, indicando a vontade de estudar em uma universidade, 
se formar e trabalhar, no entanto, observou-se contradição entre o desejo de ser independente e a forma como conseguir.

Não sei os horários, minha mãe sabe. Mas eu não sei os horários. Ela lembra os horários [...] (C.9).

\section{Não gosto muito de fazer o cateterismo (C.11).}

Evidencia-se um discurso contraditório nos relatos maternos que mostraram insegurança em permitir mais liberdade para seus filhos, comprometendo o processo de independência. Uma das mães afirma que o nascimento do irmão mais novo favoreceu a independência da filha, reconhecendo esse ganho como favorável para ambas.

Às vezes eu acho que sou eu mesma... Eu que fico... assim, e ela fica dependendo de mim. Eu deixei ela muito dependente de mim e agora para soltar está difícil... Eu já procurei terapia, mas não achei que tá muito.... porque eu vou continuar fazendo os mesmos erros (M.11).

Eu não confio de deixar ela fazer tudo sozinha (M.12).

Eu acho que foi depois que eu engravidei... Que ela viu... Ela mesma teve a necessidade de fazer as coisas sozinha. Eu não ia ter muito tempo todo para ela (M.1).

\section{DISCUSSÃO}

Todos os participantes do estudo apresentavam algum tipo de comprometimento físico ou cognitivo relacionado à $\mathrm{MMC}$, que interferia em maior ou menor grau nas suas atividades de vida cotidiana, diárias ou práticas. A vida cotidiana acontece por meio da assimilação de comportamentos e manipulação das coisas, segundo Heller (2008), que justifica que o homem nasce em um mundo já feito, com normas, condutas e comportamentos determinados em uma cotidianidade instalada, devendo, portanto, assimilar as práxis a fim de ingressar nesse processo. Assim, reconhece-se que crianças e adolescentes com MMC enfrentam experiências inerentes aos tratamentos, sucessivas hospitalizações e cuidados de saúde especiais que impedem ou limitam experiências de vida desejáveis e facilitadoras do adequado desenvolvimento.

Autores sugerem que a maioria das crianças e dos adolescentes com MMC tem capacidade para ter estilo de vida independente e autônomo, sendo fundamental que sejam incentivados, o mais precoce possível, de forma a atingir um grau de independência que lhes permita sobreviver e gerir suas vidas (CASEIRO; GONÇALVES; MALHEIRO, 2013; MOREIRA; GOMES; SÁ, 2014).

As escolas, por sua vez, exercem importante papel social como mediadoras na formação e nos cuidados com crianças e adolescentes com ou sem alteração de desen- volvimento, que necessitam ou não de equipamentos para as suas atividades escolares diárias, e devem estar aptas para receber crianças e adolescentes que apresentem ou não limitações físicas ou alterações do crescimento e desenvolvimento (MOREIRA; GOMES; SÁ, 2014).

$O$ processo de amadurecimento do ser humano relaciona-se à assimilação da manipulação das coisas e das relações sociais. É adulto quem adquire todas as habilidades imprescindíveis para a vida cotidiana em sociedade. $O$ processo de amadurecimento inicia-se nos primeiros grupos (família e escola), nos quais são desvelados os elementos da cotidianidade, sendo estabelecida uma mediação entre o indivíduo e os costumes, o que proporciona autonomia para integrações maiores, possibilitando ao homem mover-se no ambiente da sociedade em geral (HELLER, 2008).

A escola representa um primeiro local de socialização para crianças e adolescentes, favorável à construção e ao estabelecimento de relações de amizade. Trata-se de ambiente de aprendizado e troca de experiência diária, fazendo parte do cotidiano de crianças e adolescentes. Não fazer parte desse contexto ou enfrentar grandes dificuldades cotidianas nesse local, como identificado pelos participantes desse estudo, compromete a socialização, limita contatos e interfere negativamente no desenvolvimento pessoal de crianças e adolescentes com MMC. É importante considerar as alterações de aspecto cognitivo inerentes à MMC para caracterizar, compreender e promover o melhor desempenho das crianças e dos adolescentes em suas funções básicas e em atividades sociais e escolares. O processo de desenvolvimento dessas crianças e adolescentes pode ser alterado pela assimilação da manipulação das coisas e das relações sociais, influenciando diretamente o seu grau de independência e autonomia.

É importante que não só os profissionais de saúde, mas também os educadores fiquem atentos aos riscos que determinados comportamentos podem oferecer aos grupos de convivência e ao sofrimento que pode ser expresso no gerenciamento da condição crônica, valorizando e incentivando as capacidades de crianças e adolescentes (MOREIRA; GOMES; SÁ, 2014).

No estudo, todas as adolescentes independentes possuíam irmãos mais novos e as mães afirmaram que o nascimento de um outro filho determinou a conquista de autonomia dos filhos com deficiência, demonstrando a capacidade de crianças e adolescentes com MMC de promover estratégias apoiadoras no processo de viver a doença, favorecendo seu próprio cuidado. Tal aspecto, analisado à luz de Heller (1997), configura o que a autora chama de capacidade vital, ou seja, a capacidade do ser humano de aprender novas estratégias de sobrevivência. Esse aprendizado relaciona-se, diretamente, ao meio em que o ser humano está inserido. Para as adolescentes do estudo, envolveu a capacidade de adaptação e incorporação de cuidados ao seu cotidiano.

A assistência à saúde da criança encontra-se em processo de construção. Sua inserção na sociedade, assim 
como os cuidados à saúde infantil, apresentou avanços refletidos na redução da mortalidade infantil e implantação de políticas públicas. Entretanto, muitas ações ainda precisam ser pontuadas, discutidas e reorganizadas para que os avanços possam refletir as reais necessidades da população infantil, com ou sem necessidade especial de saúde (ARAUJO et al., 2014).

O nascimento de uma criança com MMC provoca grandes transformações no cotidiano familiar, modificando papéis de diferentes membros da família que devem buscar estratégias para adaptação ao novo, assimilando e manipulando novos cuidados e relações sociais, demonstrando sua capacidade vital e necessidade de reconfiguração do cotidiano (HELLER, 2008). É importante, portanto, o amparo dos profissionais da saúde com os adequados direcionamentos para cada etapa de vida, bem como, a articulação dos diferentes setores sociais. Para a conquista de um grau de independência desejada é fundamental o esclarecimento das potencialidades individuais, bem como o estabelecimento de metas viáveis para curto, médio e longo prazo, respeitando as características de cada indivíduo e de sua família. Trabalhar a construção da autonomia de indivíduos com MMC é um processo lento que exige grande esforço da família.

Investigações sugerem que a transição de cuidados da adolescência para a idade adulta deve ser iniciada aos 14 anos de idade, ou antes, caso a criança consiga compreender sua condição de saúde e demonstre interesse na continuidade dos planos de tratamento. Esse processo de transição precisa ser trabalhado de forma gradual e articulada entre os profissionais da saúde, nos diferentes níveis de atenção, e as famílias (LE; MUKHERJEE, 2015).

Na presente pesquisa, o processo de aquisição de autonomia das crianças e adolescentes participantes foi permeado por contradições evidenciadas nas diferenças entre discurso e prática. Mães, crianças e adolescentes relataram desejo de independência, no entanto, observou-se que existe a necessidade de realização de cuidados ou direcionamento por suas mães, bem como, a própria insegurança materna sobre o processo de transição de cuidados e ganho de independência e autonomia.

A atenção a essa população exige a presença de equipe multidisciplinar atuando no manejo de possíveis intercorrências clínicas, nas orientações para o autocuidado, no acompanhamento de questões neuropsicológicas e na busca pela independência e autonomia, promovendo uma experiência de vida compatível com a de seus pares de idade (CORTEZ; SCHULZ; PARDO, 2017; FALEIROS et al., 2018).

O cotidiano de crianças e dos adolescentes com MMC foi caracterizado por dificuldades e limitações, evidenciando-se, principalmente, questões de ordem estrutural no ambiente escolar e de acesso aos locais públicos. Percebe-se que mães e filhos vivem uma contradição entre ser independente e o modo de conseguir a independência, mostrando que existe a necessidade de aproximação entre os serviços de saúde, profissionais especializados e essas famílias, contribuindo para a continuidade do cuidado e a construção da independência. Deve-se considerar as dificuldades naturais existentes no processo de transição de cuidados de adolescentes, relacionados à procura de identidade, autonomia, estabelecimento de relações interpessoais e independência dos pais. Esses desafios tornam-se mais acentuados e difíceis para adolescentes com MMC que exibem alterações cognitivas e motoras, dependência prolongada dos pais, limitações nas experiências de vida e isolamento social.

Existe um desafio social enfrentado pelas mães de crianças e de adolescentes com MMC deste estudo, representado por barreiras arquitetônicas e estruturais. 0 transporte público, apesar de ser gratuito, não oferece condições de uso viável, limitando o livre ir e vir da criança e do adolescente como qualquer cidadão. As dificuldades em desempenhar atividades com seus pares de idade no ambiente escolar ou em locais públicos e de construir vínculos de amizade, gerando isolamento, foi apontado por pelo menos sete participantes. Infere-se, portanto, que as dificuldades sociais, somadas às questões de ordem cognitiva características da MMC, dificultaram a socialização desses participantes. Este trabalho apresentou como limitações: a participação no estudo restringir-se a residentes em Belo Horizonte ou cidades com até 60 km de distância, limitando generalizações; e não analisar os apoios da assistência social, o que poderia contribuir para uma rede de inclusão social dessas crianças e adolescentes. Mesmo não sendo objeto do estudo, sugere-se a ausência da assistência social.

\section{CONCLUSÃO}

A partir dos achados, reconhece-se que o cotidiano de crianças e adolescentes é permeado por um problema de ordem social, desenhado pela invisibilidade dessas crianças e adolescentes, colocando-os em condição de vulnerabilidade. Essa população necessita ultrapassar barreiras arquitetônicas dentro das próprias casas, bem como extrapolar os muros dos próprios domicílios, de modo a promover seu desenvolvimento, sua independência e participação social, transpondo a barreira da invisibilidade social. Essa tarefa deve ter a colaboração de diferentes setores sociais.

A escola é ambiente propício para o estabelecimento de relações e de desenvolvimento pessoal. A assistência social representa a garantia e o amparo legal dessas famílias para a conquista de seus direitos previstos por lei. $\mathrm{O}$ acesso aos serviços de saúde e acompanhamento por diferentes profissionais de saúde, desde a atenção básica até os serviços de reabilitação, é necessário devido a complexidade clínica e alta demanda de cuidados exigidos. Sugere-se, portanto, a efetiva integração nos âmbitos da educação, saúde e assistência social para a construção de políticas públicas direcionadas. 


\section{AGRADECIMENTOS}

À Dra Roseni Rosângela de Sena (in memoriam), professora Emérita da Escola de Enfermagem da Universidade Federal de Minas Gerais, pela orientação, dedicação e apoio para a concretização deste projeto.

\section{REFERÊNCIAS}

ARAÚJO, J. P. et al. História da saúde da criança: conquistas, políticas e perspectivas. Rev. bras. enferm., Brasília, v. 67, n. 6, p. 1000-1007, dez. 2014.

BARDIN, L. Análise de conteúdo. 4. ed. Lisboa: Edições 70, 2009. 281 p.

BRASIL. Ministério da Saúde. Conselho Nacional de Saúde. Resolução no 466, de 12 de dezembro de 2012. Aprova as diretrizes e normas regulamentadoras de pesquisas envolvendo seres humanos. Diário Oficial [da] União, Brasília, DF, 2012.

DA SILVA, V. C.; DE OLIVEIRA-MENEGOZZO, J. M. Defeitos do fechamento do tubo neural: evolução da incidência no brasil. Saúde Colet., São Paulo, v. 9, n. 56, p. 56-60, 2012.

CASEIRO, J.; GONÇALVES, T.; MALHEIRO, M. I. Construção da Autonomia dos Jovens Portadores de Spina Bífida-O que dizem os jovens e seus pais/cuidadores. Enferm. Glob., Murcia, v. 30, p. 121-34, 2013.

COPP, A. J.; GREENE, N. de. Neural tube defects-disorders of neurulation and related embryonic processes. Wiley Interdisciplinary Reviews: Developmental Biology, [s.I], v. 2, n. 2, p. 213-227, 2013.

CORTEZ, C.; SCHULZ, R.; PARDO, R. Espina bífida en adultos: Una revision de las alteraciones musculoesqueléticas. Arch. Med., Oviedo, v. 13, n. 2, p. 12, 2017.

FALEIROS, F. et al. Factors influencing the use of intermittent bladder catheterization by individuals with spina bifida in Brazil and Germany. Rehabil Nurs., Glenview, 2018.
FERREIRA, F. R. et al. Independência funcional de crianças de um a quatro anos com mielomeningocele. Fisioter. Pesqui., São Paulo, v. 25, n. 2, p. 196-201, 2018.

FIEGGEN, G. et al. Spina bifida: A multidisciplinary perspective on a many-faceted condition. S. Afr. Med. J., Cape Town, v. 104, n. 3, p. 212-217, 2014

HELLER, A. O cotidiano e a história. 8.ed. São Paulo: Terra e Paz, 2008. $158 p$.

HELLER, A. Socilogía de la vida cotidiana. 62. ed. Barcelona: Editora Península, 1977. 418p.

LE, J. T.; MUKHERJEE, S. Transition to adult care for patients with spina bifida. Phys. Med. Rehabil. Clin. North Am., Philadelphia, v. 26, n. 1, p. 29-38, 2015.

MINAYO, M. C. de S. O desafio do conhecimento: pesquisa qualitativa em saúde. 12. ed. São Paulo: Hucitec, 2010.

MOHD-ZIN, S. W. et al. Spina bifida: pathogenesis, mechanisms, and genes in mice and humans. Ric. Sci., Rome, v. 2017, 2017.

MOREIRA, M. C. N.; GOMES, R; SÁ, M. R. C. de. Doenças crônicas em crianças e adolescentes: uma revisão bibliográfica. Ciênc. Saúde Colet., Rio de Janeiro, v. 19, p. 2083-2094, 2014.

OAKESHOTT, P. et al. Walking and living independently with spina bifida: a 50 year prospective cohort study. Dev. Med. Child Neurol., London, 2019.

ORIOLI, I. M. et al. Effects of folic acid fortification on spina bifida prevalence in Brazil. Birth Defects Res. A. Clin. Mol. Teratol., Hoboken, v. 91, n. 9, p. 831-835, 2011.

WAGNER, R. et al. Perception of secondary conditions in adults with spina bifida and impact on daily life. Disabil. Health J., New York, v. 8, n. 4, p. 492-498, 2015.

Submetido em: 23/09/2019

Aceito em: 08/08/2020 